\title{
Observations on Ocys monzinii Magrini \& Vigna Taglianti, 2006, oreophylous species from the Lombard Pre-Alps (Coleoptera: Carabidae, Bembidiina)
}

\author{
Paolo MAGRINI ${ }^{1, *}$, Mario GROTTOLO ${ }^{2}$, Davide PEDERSOLI ${ }^{3}$ \\ ${ }^{1}$ Museo di Storia naturale dell'Università di Firenze, Sezione di Zoologia “La Specola” - Via Romana 17, I-50125 Firenze, Italy; \\ or: Via Gianfilippo Braccini 7, I-50141 Firenze, Italy - duvalius@paolomagrini.it \\ ${ }^{2}$ Centro Studi Naturalistici Bresciani, clo Museo di Scienze Naturali - Via Ozanan, 4 -25128 Brescia, Italy; or: Via M. Malvestiti 28 \\ 25123 Brescia, Italy - mario.grottolo@libero.it \\ ${ }^{3}$ Centro Studi Naturalistici Bresciani, clo Museo di Scienze Naturali - Via Ozanan, 4 -25128 Brescia, Italy; or: Via Leutelmonte 42, \\ 25040 Esine (Brescia), Italy - pedux_davide@yahoo.it \\ * Corresponding author
}

\begin{abstract}
New iconographic data are here reported and a new record is given (Monte Alben, Bergamo Pre-Alps) for Ocys monzinii Magrini \& Vigna Taglianti, 2006; beside, a new morphometric table is provided after newly collected material.
\end{abstract}

Key words: Carabidae, Ocys monzinii, new data, Italy, oreophylous fauna.

\section{Introduction}

Ocys monzinii Magrini \& Vigna Taglianti, 2006 was described on the basis of a single, slightly immature male, collected on Monte Resegone (Pre-Alps of Lecco, Lombardy region, Italy), by Vittorio Monzini; the same species, subsequently found by Riccardo Monguzzi, has been recorded from Corni di Canzo (Lombardy, Como Province): Magrini \& Petruzziello (2018: 57). More recently, two of us (MG and DP) found a small series close to the type locality (Monte Resegone) and also on Monte Alben (Lombardy, Bergamo Province; new record), both situated in the Pre-Alps of Lombardy. The population from this latter locality shares small differences compared to the two populations already known: fifth and sixth elytral striae slightly less impressed, meshes of microreticulation a little smaller and more transverse. Nevertheless these are small and, above all, inconstant differences and we can see no reason for considering the specimens from Monte Alben as members of a different species. Since the only available illustration of Ocys monzinii is the picture of the aedeagus of the holotype (immature), we consider it helpful to provide new iconographic data of habitus and male genitalia, based on the new material collected (Figs 1-6), while for female genitalia (spermatheca) we refer to the illustration in Magrini \& Petruzziello (2018: 54). In Fig. 10 we also add the distribution map of $O$. monzinii as given in the latter paper cited above, with an eastern exten- sion of its range. The examination of new material enabled us to draft a more complete morphometric Table, since at present only the morphometric characters of the holotype where known. For the morphology in general of the species we remand to the original description: Magrini \& Vigna Taglianti 2006: 186 . The Table 1 shows that this species is very variable from a morphological point of view, but in spite of this, the fundamental characters which easily identify this species are always constant: short and broad elytra, with very rounded humera, dark copper-green, with reddish head and pronotum (reddish-brown general colouration normally in immature specimens).

\section{Materials and Methods}

The material examined can be found in the following collections.
CM Coll. P. Magrini (Firenze)
CG Coll. M. Grottolo (Brescia)
CP Coll. D. Pedersoli (Esine, Brescia)
CMM Coll. V. Monzini (San Giuliano Milanese, Milano)
CMO Coll. R. Monguzzi (Milano)

We also report below the abbreviations of the morphometric measures shown in the Table and in the description. L total length, from apex of mandibles to elytral extremity 

LA
antennal length
PL length of pronotum, measured along medial line
PMW maximum witdth of pronotum
PB width of base of pronotum, measured be-
EL length of elytra, from base to sutural angle
EW maximum width of elytra
HMW maximum width of head at eye level
PMW/PL ratio maximum width/length of pronotum
EL/EW ratio length/width of elytra
EW/PMW ratio width of elytra/width of pronotum
LE length of aedeagus
SP length of spermatheca
AN length of antennal segment

The macro-photographs have been made by one of us (PM) using digital cameras Nikon D2X and D800, mounted on a optical binocular microscope Nikon Labophot II or a stereomicroscope Nikon SMZ 1000, with diaphragm objectives; genitalia were mounted in euparal, on vinyl acetate.

Ocys monzinii Magrini \& Vigna Taglianti, 2006 (Figs 1-6)

Material examined: Italy: Lombardy: Holotypus $\hat{\sigma}$, Val Caldera, Northern slope of Monte Resegone, m 1700 a.s.l. (Lecco), 3.V.1997, leg. V. Monzini (CMM); 2 우으, Corni di Canzo m 1300 a.s.l., Triangolo Lariano (Como), 17.XI.2009, leg. R. Monguzzi (CMO)(CM); 3 ồ, SW slope of Pizzo Brumano m 1750 a.s.l., Brumano (Lecco), 4.XI.2017, leg. D. Pedersoli (CP)(CG); 1 ㅇ, same data, 24.IX.2018 (CP); $2 \widehat{\partial} \widehat{\partial}$, ridge between Punte Cermenati and Stoppani, m 1785 a.s.l. (Lecco), 15.IX.2019, leg. D. Pedersoli (CP)(CM). Monte Alben m 1750 a.s.l., Colle dei Brassamonti (Oneta, Bergamo): 1 q, 10.X.2015, leg. D. Pedersoli (CP); 1 त, 17.X.2015, leg. D. Pedersoli (CM); 1 गै, 1 ㅇ, 18.X.2015, leg. D. Pedersoli \& M. Grottolo (CP)(CG); 1 ô, 14.V.2016, leg. M. Grottolo (CG); 1 q, 27.V.2017, leg. M. Grottolo (CG); 3 đิ ô, 14.V.2017, leg. D. Pedersoli \& M. Grottolo (CP)(CG)(CM); 1 $\widehat{0}, 2$ 우우, 28.X.2017, leg. D. Pedersoli (CP); 1 ㅇ, 27.V.2018, leg. D. Pedersoli (CP); 1 ๙ , 1 क , 15.IX.2018, leg. D. Pedersoli (CP)(CM); 1 + , 21.IV.2019, leg. D. Pedersoli (CP).
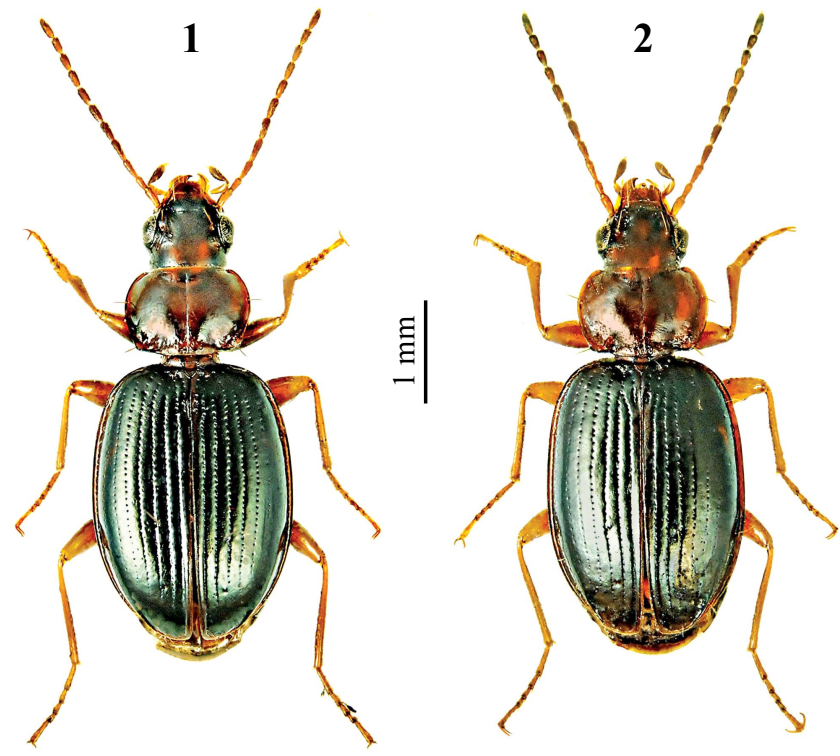

Figs 1-2 - Habitus of Ocys monzinii Magrini \& Vigna Taglianti, 2006, ô: 1, Lombardy (Lecco), Monte Resegone, m 1750 a.s.l. (Brumano), surr. of Pizzo Brumano SW slope, 4.XI.2017, leg. D. Pedersoli (CP); 2, Lombardy (Bergamo), Monte Alben, m 1750 a.s.l. (Colle dei Brassamonti, Oneta), 14.V.2017, leg. M. Grottolo $(\mathrm{CM})$.

\section{Ocys monzinii Magrini \& Vigna Taglianti, 2006}

\section{Ecological notes}

At present, in the Monte Alben massif, O. monzinii is known only from nearby Colle Brassamonti, in a restricted area characterised by white outcrops of the "Dolomia Principale" formation (dolomite), where the species is collected under free-standing stones and also small pebbles, often clinging to the lower face.

The species seems to prefer grass-free niches, with soil of sand originated by rock disintegration, specially along the stretches of Dryas octopetala Linnaeus, 1753. It probably has night habits, as we have not observed active specimens during the day in the course of our researches and different exemplars were found under the same stone or in any case within a few centimetres of each other. Most of the more fruitful samplings were made in humid, foggy, sometimes rainy days, or even with a few patches of fresh

Table 1 - Morphometric measures in millimeters of the specimens examined. N=20 measured specimens.

\begin{tabular}{|c|c|c|c|c|c|c|c|c|c|c|c|c|c|c|c|c|c|c|c|}
\hline & $\mathrm{L}$ & LA & $\frac{\mathrm{L}}{\mathrm{LA}}$ & PMW & PL & PB & $\frac{\mathrm{PMW}}{\mathrm{PL}}$ & EL & EW & $\frac{\mathrm{EL}}{\mathrm{EW}}$ & $\frac{\text { EW }}{\text { PMW }}$ & LE & SP & HMW & $\begin{array}{c}\text { AN } \\
1^{\circ}\end{array}$ & $\begin{array}{c}\mathrm{AN} \\
2^{\circ}\end{array}$ & $\begin{array}{c}\mathrm{AN} \\
3^{\circ}\end{array}$ & $\begin{array}{c}\mathrm{AN} \\
4^{\circ}\end{array}$ & $\begin{array}{l}\text { AN } \\
11^{\circ}\end{array}$ \\
\hline Holotypus $\widehat{\curvearrowright}$ & 4,14 & 1,97 & 2,10 & 1,12 & 0,77 & 0,93 & 1,45 & 2,47 & 1,75 & 1,41 & 1,56 & 0,80 & & 0,83 & 0,19 & 0,16 & 0,19 & 0,20 & 0,19 \\
\hline $\min$. & 3,55 & 1,80 & 1,96 & 0,96 & 0,67 & 0,77 & 1,40 & 2,31 & 1,57 & 1,30 & 1,51 & 0,61 & 0,17 & 0,73 & 0,16 & 0,12 & 0,17 & 0,17 & 0,17 \\
\hline $\max$. & 4,60 & 2,17 & 2,15 & 1,25 & 0,86 & 0,99 & 1,46 & 2,70 & 1,92 & 1,41 & 1,63 & 0,87 & 0,19 & 0,93 & 0,20 & 0,17 & 0,22 & 0,24 & 0,21 \\
\hline mean & 4,24 & 2,06 & 2,05 & 1,15 & 0,81 & 0,92 & 1,42 & 2,53 & 1,83 & 1,37 & 1,57 & 0,79 & 0,18 & 0,85 & 0,18 & 0,15 & 0,19 & 0,20 & 0,20 \\
\hline
\end{tabular}


3

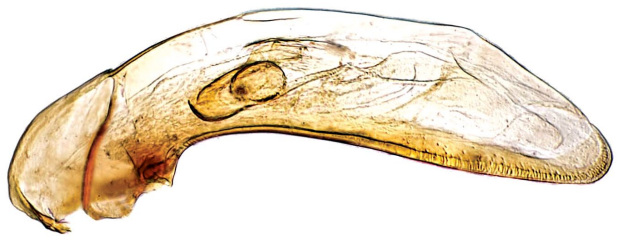

4

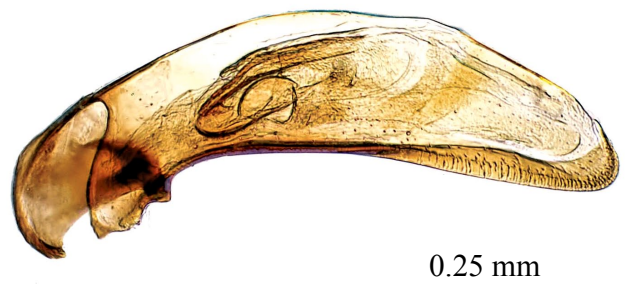

6
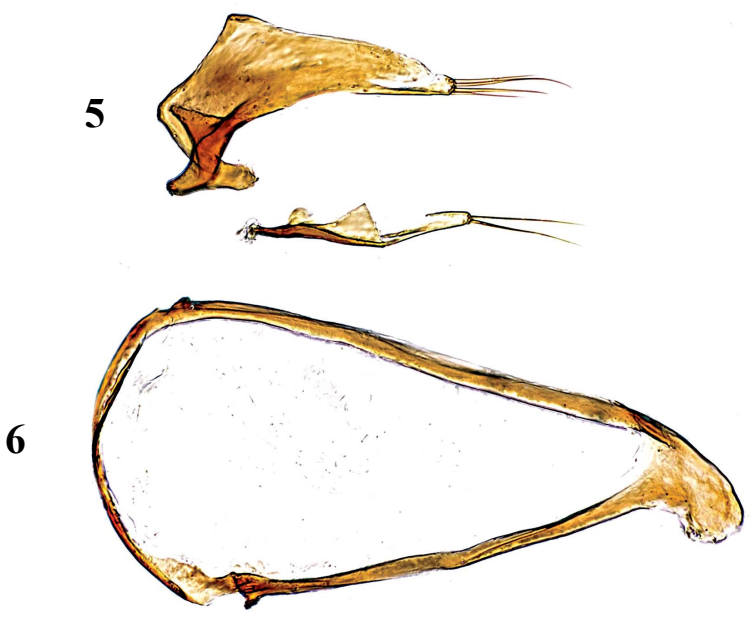

Figs 3-6 - Ocys monzinii Magrini \& Vigna Taglianti, 2006: 3, aedeagus, lateral view mounted in euparal on vinyl acetate, from Monte Resegone; 4, ditto, from Monte Alben; 5, parameres, from Monte Alben; 6, urite IX, from Monte Alben.

snow on the ground; during the few researches carried out on sunny and dry days, we found only a few specimens under the sunken stones. Collection was fruitful only between the second half of September to the beginning of November, and from early April to late May, as we found mature specimens in both of these two periods. Not many researches were carried out in summer time, as they already gave poor results at the end of spring and no specimens were found in pit falls during the warmer months, as the insects were probably inactive due to the dryness of the soil. It is noticeable that in the passage between the Monte Alben to the Forca Pass, the outcropping rock changes abruptly for a few dozen meters, becoming darker and stratified, with higher water retention capacity and consequent, at least apparently, lack of $O$. monzinii. These observations could provide a valid explanation of why this taxon is not easy to sample, although it is present in two widely investigated mountain ranges.

Such observations of $O$. monzinii on M. Alben, after a careful study of the locality, both from a geological and vegetation point of view, allowed one of us (DP) to col-
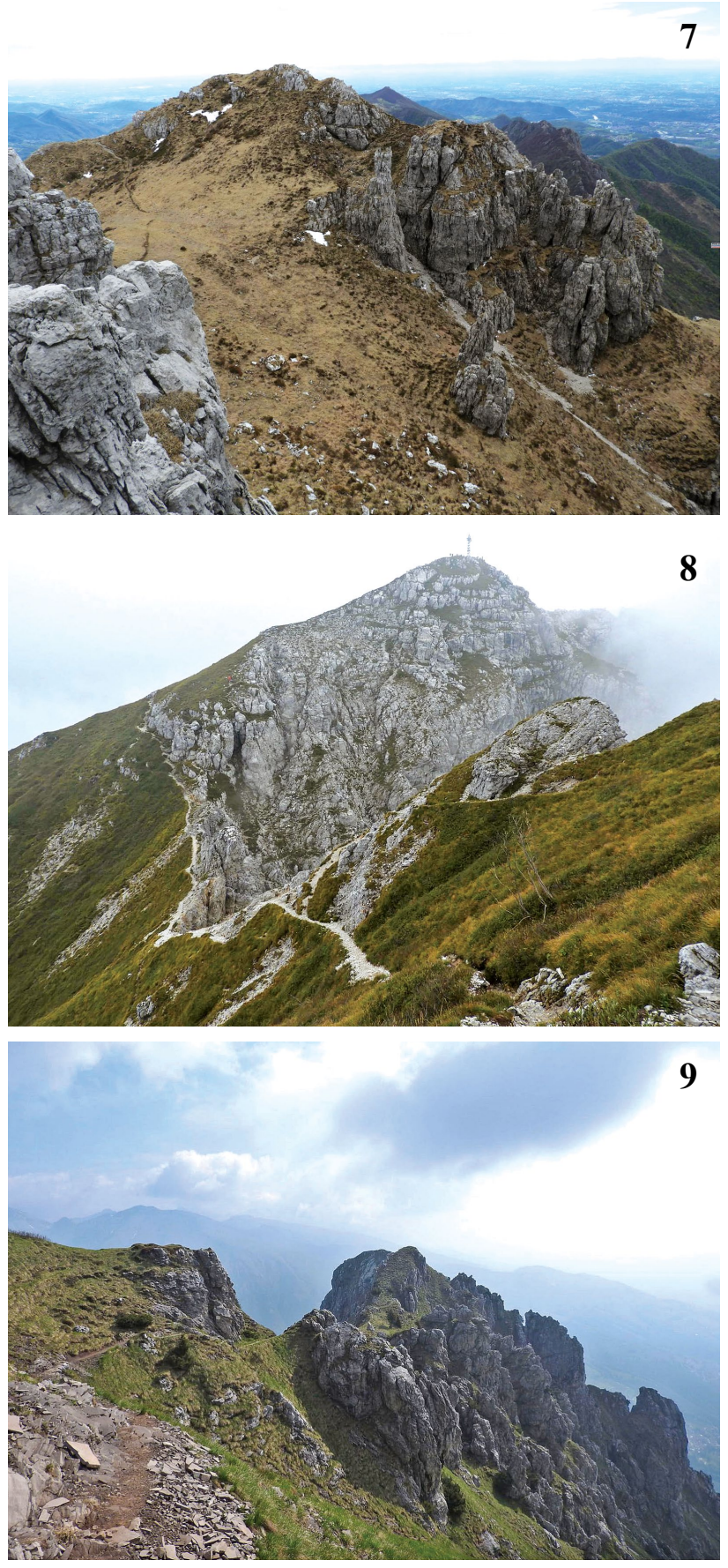

Figs 7-9 - Habitat of Ocys monzinii: 7, Monte Resegone, SW slope of Pizzo Brumano; 8, Monte Resegone, ridge between Punte Cermenati and Stoppani; 9, Monte Alben, Colle dei Brassamonti.

lect three males of this species on Monte Resegone in the first targeted research, while it had been previously known from this massif for the male holotype only, in spite of the numerous field researches previously carried out by several colleagues. These initial finds were followed by the collection of one female and two other males during the following years. 


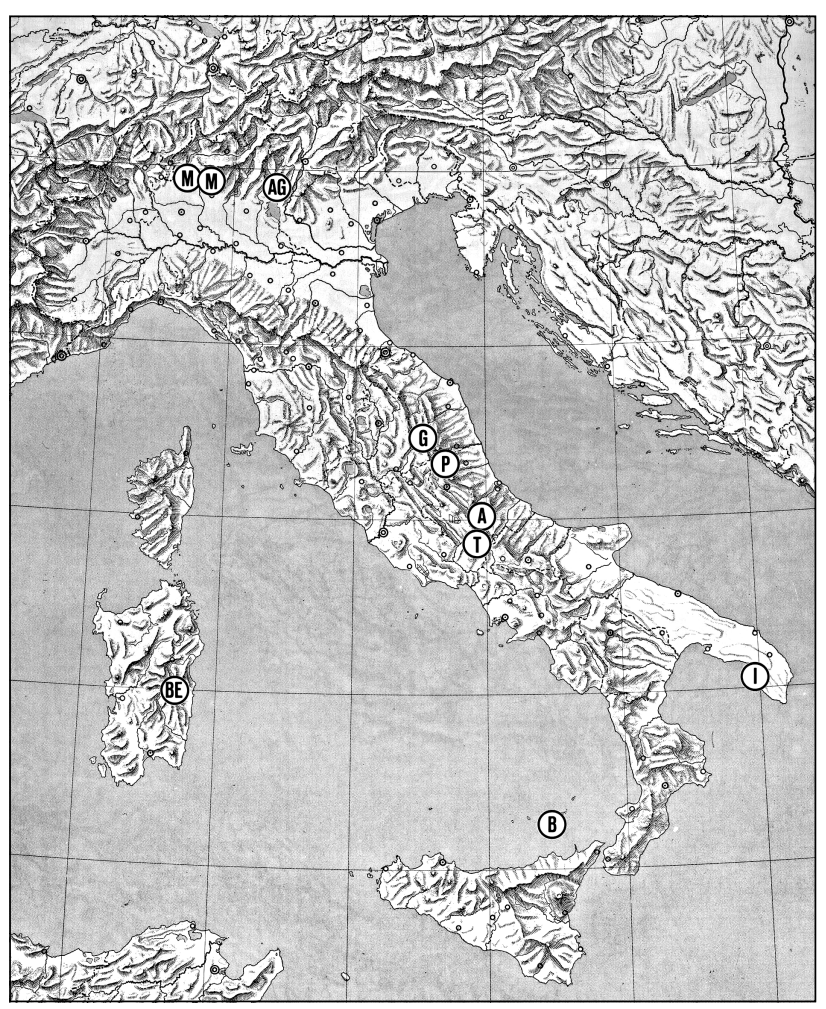

Fig. 10 - Distribution in Italy of the species of the genus Ocys with restricted area: P, Ocys pennisii Magrini \& Vanni, 1989; I, Ocys inguscioi Magrini \& Vanni, 1992; T, Ocys tassii Vigna Taglianti, 1995; B, Ocys beatricis Magrini, Cecchi \& Lo Cascio, 1998; A, Ocys angelae Magrini \& Vigna Taglianti, 2006; G, Ocys gubellinii Magrini \& Vigna Taglianti, 2006; M, Ocys monzinii Magrini \& Vigna Taglianti, 2006; BE, Ocys berbecum Magrini \& Degiovanni, 2010; AG, Ocys agostii Magrini \& Petruzziello, 2018. [The species with widespread range in Italy, not reported in the map are: O. harpaloides (Audinet-Serville, 1821), occurring in whole Italy and Corsica; O. quinquestriatus (Gyllenhal, 1810) and $O$. reticulatus (Netolitzky, 1917), occurring in most of Italy (see key in Magrini \& Petruzziello 2018: 59); $O$. tachysoides (Antoine, 1933), known from Western Europe and Northen Africa, close to $O$. harpaloides, not yet recorded for Italy (Maddison \& Anderson 2016), but it could be present].

Regarding the associated Coleoptera on Monte Alben observed in the course of these field researches, it is interesting to report the following species - Carabidae: Cychrus angustatus Hoppe, 1882; Leistus (Pogonophorus) spinibarbis spinibarbis (Fabricius, 1775); Oreonebria lombarda Daniel \& Daniel, 1890; Broscosoma relicta Weissmandl, 1935; Trechus bergamascus Jeannel, 1827; Boldoriella (Insubrites) binaghii binaghii Buccia- relli, 1978; Duvalius winklerianus winklerianus Jeannel, 1926; Platynus teriolensis (Daniel \& Daniel, 1898); Laemostenus janthinus coeruleus (Dejean, 1828); Laemostenus insubricus Ganglbauer, 1903; Laemostenus macropus (Chaudoir, 1859); Pterostichus dissimilis Villa \& Villa, 1833; Pterostichus lombardus Daniel \& Daniel, 1900; Pterostichus (Oreophilus) multipunctatus (Dejean, 1828); Tanythrix edurus (Dejean, 1828); Abax (Abax) arerae Schauberger, 1927; Abax (Abax) baenningeri Schauberger, 1927; Abax (Abax) fiorii Jacobson, 1906; Amara alpestris alpestris Villa \& Villa, 1933; Cymindis (Cymindis) cingulata Dejean, 1825. Leiodidae: Leiodes (Oosphaerula) sp. Leptodirinae: Pseudoboldoria barii Focarile, 1950; Pseudoboldoria kruegeri orobica Vailati, 1988. Scydmaenidae: Euconnus (Cladoconnus) sp. Pselaphidae: Bryaxis emilianus (Stolz, 1926); Pselaphostomus bergamascus Besuchet, 1980; Elateridae: Athous (Orthathous) orobicus Platia, 2015. Omalisidae: Omalisus victoris (Mulsant, 1850). Chrysomelidae: Cryptocephalus (Cryptocephalus) barii Burlini, 1948. Staphylinidae: Amphichroum canaliculatum (Erichson, 1840); Lesteva omissa Rey, 1880; Quedius ochropterus Erichson, 1840. Curculionidae (several species of Otiorhynchus spp.; Leiosoma spp.).

Aknowledgements - With great pleasure we wish to dedicate this note to the memory of our friend Mauro Agosti (Brescia), talented entomologist prematurely deceased, who accompanied one of us (DP) on Monte Alben for the first time, in search of Trechus specimens (without expecting to find Ocys). Special thanks are due to Gianantonio Leoni (Cologno al Serio, Bergamo), great expert on the flora of the Orobie mountains and lover of mountain nature, with whom one of us (DP) carried out the first excursion on the Resegone mountain, receiving information on the environments most similar to Colle Brassamonti of Monte Alben, and thus suitable for collecting Ocys monzinii. Thanks also to our friends and colleagues Riccardo Monguzzi (Milan) and Vittorio Monzini (San Giuliano Milanese, Milan) for the material loaned in study.

\section{References}

Maddison D. R., Anderson R. 2016. Hidden species within the genus Ocys Stephens: the widespread species O. harpaloides (Audinet-Serville) and O. tachysoides (Antoine) (Coleoptera, Carabidae, Bembidiini). Deutsche entomologische zeitschrift, 63 (2): 287-301.

Magrini P., Petruzziello L. 2018. Un nuovo Ocys Stephens, 1828 orofilo delle Prealpi Lombarde (Coleoptera, Carabidae, Bembidiina). Giornale italiano di Entomologia, 15 (63): 49-62.

Magrini P., Vigna Taglianti A. 2006. Tre nuovi Ocys orofili italiani (Coleoptera Carabidae). Bollettino della Società entomologica italiana, 138 (3): 181-195. 